\title{
The changing epidemiology of hepatocellular carcinoma in Greece
}

\author{
George E. Markakis ${ }^{a}$, Andreas Koulouris ${ }^{b}$, Maria Tampaki ${ }^{a}$, Evangelos Cholongitas $c$, Melanie Deutsch ${ }^{\mathrm{d}}$, \\ George V. Papatheodoridis ${ }^{a}$, John Koskinas ${ }^{d}$
}

Medical School, National and Kapodistrian University of Athens; Medical School, University of Crete, Greece

Abstract

\section{Introduction}

Liver cancer is the sixth most common cancer and the third leading cause of cancer death globally [1]. Hepatocellular carcinoma (HCC) represents $75-85 \%$ of all liver cancer cases. Prognosis remains poor, with an overall ratio of mortality to

${ }^{a}$ Department of Gastroenterology, Medical School, National and Kapodistrian University of Athens (George E. Markakis, Maria

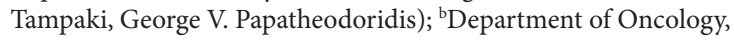
Medical School, University of Crete (Andreas Koulouris);

${ }^{\mathrm{c}} 1^{\text {st }}$ Department of Internal Medicine, Medical School, National and Kapodistrian University of Athens (Evangelos Cholongitas); ${ }^{d} 2^{\text {nd }}$ Department of Internal Medicine, Medical School, National and Kapodistrian University of Athens (Melanie Deutsch, Ioannis Koskinas), Greece

\section{Conflict of Interest: None}

Correspondence to: John Koskinas, Professor, Second Department of Internal Medicine, Medical School of National \& Kapodistrian University of Athens, Hippokratio General Hospital, Vas. Sofias 114, Athens 11527, Greece, e-mail: koskinasj@yahoo.gr

Received 27 May 2021; accepted 28 September 2021; published online 6 December 2021

DOI: https://doi.org/10.20524/aog.2021.0680 incidence of 0.91 , although the accelerated introduction of novel therapeutic agents is expected to lead to a more favorable landscape. Over $70 \%$ of new HCC diagnoses concern Asian populations, while southern Europe has an intermediate age-standardized ratio of 6.8 per 106 people. HCC is mainly associated with hepatitis $\mathrm{B}$ and $\mathrm{C}$ viruses ( $\mathrm{HBV}$ and $\mathrm{HCV}$ ), excessive alcohol consumption, diabetes, and nonalcoholic fatty liver disease (NAFLD), with wide geographical variations. In the age of effective treatment for HBV and HCV infection, with NAFLD becoming the leading cause of chronic liver disease in western countries, HCC major risk factors are possibly changing [2-5].

Several studies have evaluated HCC characteristics in Greece from 1973-2000 $(\mathrm{n}=1558)$ with $\mathrm{HBV}$ and HCV prevalence ranging from $46-71 \%$ and from $4-21 \%$, respectively [6,7]. Raptis et al [6] showed a statistically significant decrease in $\mathrm{HBV}$ prevalence (from 59\% to 52\%) and an increase in $\mathrm{HCV}$ prevalence (from $11 \%$ to $22 \%$ ) in HCC patients from before to after 1995. Additionally, Karageorgos et al [8] studied a closed, homogenous population of 600,000 inhabitants in the south of Greece from 1994 to 2014 and found an increase in the incidence of HCC, due to a gradual increase in the incidence of HBV- and alcohol- related cases (both from $22 \%$ to $27 \%$ ), as well as an impressive increase in the incidence of NAFLDrelated cases (from $0 \%$ to $23 \%$ ). 
In this study, considering the overall decline in $\mathrm{HBV}$ prevalence in Greek patients during the last decades $[9,10]$ and the rising prevalence of NAFLD [8,11-13], we evaluated possible changes in the etiology and characteristics of HCC during the last 2 decades. In addition, we compared our findings with data reported in Greek studies from 1973-2000.

\section{Patients and methods}

We retrospectively reviewed the available records of all patients with HCC evaluated in 2 academic hospitals of Athens, Greece ("Laiko" General Hospital and "Hippokratio" General Hospital), between 2000 and 2019. The retrospective collection of patient data was approved by the Institutional Review Board of the National and Kapodistrian University of Athens and the Scientific Committees of both hospitals.

Data were extracted from patient records based on a predefined form, including age, sex, race, weight, height, liver disease, presence of cirrhosis, portal thrombosis, performance status, portal hypertension, Child-Pugh score and $\alpha$-fetoprotein (AFP) at HCC diagnosis, date of liver disease and HCC diagnosis, method of cirrhosis and HCC diagnosis, and HCC characteristics (number, size and segment of nodules, microvascular invasion, tumor differentiation, extrahepatic metastasis).

The diagnosis of cirrhosis and HCC was based on radiological (computed or magnetic tomography) and/or histological findings. Chronic liver diseases were grouped into 3 categories: HBV, HCV and non-viral liver disease (nvLD). The diagnosis of liver disease was established by the treating hepatologist in the patients' records. As per definition, chronic HBV diagnosis and evaluation was based on serologic tests for $\mathrm{HBs} \mathrm{Ag}$, anti-HBs, $\mathrm{HBeAg}$, anti-HBe, anti-HBc and polymerase chain reaction (PCR) for HBV-DNA. The diagnosis of chronic $\mathrm{HCV}$ infection was based on the detection of both anti-HCV and serum HCV-RNA by PCR. NAFLD, alcoholic liver disease (ALD), autoimmune liver diseases, and hemochromatosis were diagnosed as per standard diagnostic criteria (patient's history, comorbidities, autoantibodies, plasma proteins, histological and radiological characteristics). In patients with no certain etiology of cirrhosis, liver disease was characterized as unknown.

Patients with HBV infection and concomitant other liver diseases were assigned to the HBV group, while patients with $\mathrm{HCV}$ infection and concomitant other liver diseases (except HBV infection) were assigned to the HCV group. The remaining patients were included in the nvLD group, including those with unknown liver disease.

Patients were clustered into 2 time periods according to the date of HCC diagnosis: before 2011 (period A) and after 2011 (period B). Patient and HCC characteristics were compared between the 2 time periods. Lastly, the results of this study were compared with data from previous Greek studies including HCC patients, diagnosed between 1973 and $2000[6,7,14-20]$.

\section{Statistical analysis}

For data analysis we used IBM SPPS statistics (IBM Corp. Released 2020. IBM SPSS Statistics for Mac, Version 27.0.1. Armonk, NY: IBM Corp). The chi-squared and Fisher's exact tests were used to compare nominal and ordinal characteristics of the study population. Continuous variables were tested for normality with the Shapiro-Wilk $(n<50)$ or KolmogorovSmirnov $(\mathrm{n} \geq 50)$ test. The $t$-test and Mann-Whitney $U$ (or Kruskal-Wallis exact tests) were used for normally and non-normally distributed variables, respectively. All tests were 2 -sided. A difference with a P-value less than 0.05 was considered to be significant. When multiple proportions were compared, Bonferroni adjustment was applied. The total number of patients shown in the different tables may differ because of missing data in specific covariates.

\section{Results}

We identified 300 consecutive HCC patients. Their median age was 64 years, $258(86 \%)$ of them were male and 119 (96.7\%) Caucasian. Patients' characteristics at the time of HCC diagnosis are summarized in Table 1. Regarding the different causes of chronic liver disease, HCC was associated with chronic infections with hepatitis viruses in 211 (70.3\%) and non-viral liver disease (nvLD) in 89 (29.7\%) patients. In particular, 134 patients $(44.7 \%)$ had chronic HBV and 77 patients (25.7\%) chronic HCV infection, while the majority of patients with nvLD had ALD and NAFLD. Cirrhosis was present in $240(85.7 \%)$ of the patients at the time of HCC diagnosis. Child class A was present in 93 (49.2\%), class B in $72(38.1 \%)$, and class C in $24(12.7 \%)$ of the patients with cirrhosis. HCC diagnosis was based on typical findings by radiological imaging (computed tomography and/or magnetic resonance scan) in $82(72.6 \%)$ and on histological findings after guided liver biopsy in the remaining $31(27.4 \%)$ patients. The grade of HCC differentiation was low in $13.3 \%$, intermediate in $56.7 \%$, and high in $30 \%$ of patients with available liver biopsy. The median AFP value at the time of HCC diagnosis was $78 \mathrm{ng} /$ $\mathrm{mL}$, while $39.1 \%$ of the patients had an AFP value greater than $350 \mathrm{ng} / \mathrm{mL}$. The largest HCC nodule was smaller than $3 \mathrm{~cm}$ in $17.9 \%$, between $3 \mathrm{~cm}$ and $5 \mathrm{~cm}$ in $32.5 \%$, and larger than $5 \mathrm{~cm}$ in $49.6 \%$ of the patients, whereas $19.6 \%$ of patients had more than 3 nodules. At the time of HCC diagnosis, portal vein thrombosis was detected in $19.6 \%$ and metastases in $11.4 \%$ of the patients.

\section{Comparison among liver diseases}

Comparisons of patient and tumor characteristics among HBV, HCV and nvLD patients are shown in Table 2. The median age at diagnosis was 66, 57 and 69 years for HBV, HCV and nvLD patients, respectively. Age at diagnosis differed significantly between $\mathrm{HCV}$ and $\operatorname{nvLD}(\mathrm{P}=0.003)$ and between 
Table 1 Changes in characteristics of hepatocellular carcinoma in Greece, 2000-2019

\begin{tabular}{|c|c|c|c|c|}
\hline Characteristics & $2000-2011$ & 2012-2019 & Total & P-value \\
\hline $\mathrm{N}(\%)$ & $94(31.6)$ & $203(68.4)$ & 300 & \\
\hline $\begin{array}{l}\text { Age, median (IQR) } \\
\quad<60, \mathrm{n}(\%) \\
\geq 60, \mathrm{n}(\%)\end{array}$ & $\begin{array}{l}63(14) \\
16(39) \\
25(61)\end{array}$ & $\begin{array}{c}66(17) \\
23(29.5) \\
55(70.5)\end{array}$ & $\begin{array}{c}64(15) \\
40(33.1) \\
81(66.9)\end{array}$ & 0.311 \\
\hline Male, n (\%) & $85(90.4)$ & $171(84.2)$ & $258(86)$ & 0.205 \\
\hline $\begin{array}{l}\text { Race, } \mathrm{n}(\%) \\
\text { Caucasian } \\
\text { Black } \\
\text { Asian } \\
\text { Other }\end{array}$ & $\begin{array}{c}46(100) \\
0 \\
0 \\
0\end{array}$ & $\begin{array}{c}70(94.6) \\
1(1.4) \\
1(1.4) \\
2(2.7)\end{array}$ & $\begin{array}{c}119(96.7) \\
1(0.8) \\
1(0.8) \\
2(1.6)\end{array}$ & 0.818 \\
\hline $\begin{array}{l}\text { Liver disease, n (\%) } \\
\text { Viral } \\
\text { HBV } \\
\text { HCV } \\
\text { Non-viral }\end{array}$ & $\begin{array}{l}73(77.7) \\
45(47.9) \\
28(29.8) \\
21(22.3)\end{array}$ & $\begin{array}{l}139(67) \\
89(43.8) \\
47(23.2) \\
67(33)\end{array}$ & $\begin{array}{l}211(70.3) \\
134(44.7) \\
77(25.7) \\
89(29.7)\end{array}$ & 0.075 \\
\hline Cirrhotic, n (\%) & $68(84)$ & $169(86.2)$ & $240(85.7)$ & 0.707 \\
\hline $\begin{array}{l}\text { Child-Pugh score, n (\% } \\
\text { A } \\
\text { B } \\
\text { C }\end{array}$ & $\begin{array}{c}15(65.2) \\
5(21.7) \\
5(13)\end{array}$ & $\begin{array}{l}78(47.3) \\
67(40.6) \\
20(12.1)\end{array}$ & $\begin{array}{l}93(49.2) \\
72(38.1) \\
24(12.7)\end{array}$ & 0.208 \\
\hline $\begin{array}{l}\text { HCC diagnosis, n (\%) } \\
\text { CT } \\
\text { MRI } \\
\text { Biopsy }\end{array}$ & $\begin{array}{c}14(35) \\
11(27.5) \\
15(37.5)\end{array}$ & $\begin{array}{l}22(30.1) \\
35(47.9) \\
16(21.9)\end{array}$ & $\begin{array}{l}36(31.9) \\
46(40.7) \\
31(27.4)\end{array}$ & 0.073 \\
\hline $\begin{array}{l}\text { Nodules, } \mathrm{n}(\%) \\
<3 \text { nodules } \\
\geq 3 \text { nodules } \\
\text { diameter: }<3 \mathrm{~cm} \\
\geq 3,<5 \mathrm{~cm} \\
\geq 5 \mathrm{~cm}\end{array}$ & $\begin{array}{c}52(69.3) \\
23(30.7) \\
2(5.3) \\
19(50) \\
17(44.7)\end{array}$ & $\begin{array}{l}169(84.5) \\
31(15.5) \\
20(23.5) \\
21(24.7) \\
44(51.8)\end{array}$ & $\begin{array}{l}222(80.4) \\
54(19.6) \\
22(17.9) \\
40(32.5) \\
61(49.6)\end{array}$ & $\begin{array}{l}0.006 \\
0.005\end{array}$ \\
\hline $\begin{array}{l}\text { Location (lobe), n (\%) } \\
\text { Right } \\
\text { Left } \\
\text { Right and Left } \\
\text { AFP, median (IQR) } \\
<350 \mathrm{ng} / \mathrm{mL}, \mathrm{n}(\%) \\
\geq 350 \mathrm{ng} / \mathrm{mL}, \mathrm{n}(\%)\end{array}$ & $\begin{array}{l}50(63.3) \\
12(15.2) \\
17(21.5) \\
109(490) \\
36(57.1) \\
27(42.9)\end{array}$ & $\begin{array}{c}45(60.8) \\
12(16.2) \\
17(23) \\
70(1921) \\
112(62.6) \\
67(37.4)\end{array}$ & $\begin{array}{l}95(61.7) \\
25(16.2) \\
34(22.1) \\
78(1086) \\
148(60.9) \\
95(39.1)\end{array}$ & $\begin{array}{l}0.946 \\
0.456\end{array}$ \\
\hline $\begin{array}{l}\text { Differentiation, n (\%) } \\
\text { Low } \\
\text { Intermediate } \\
\text { High }\end{array}$ & $\begin{array}{c}0 \\
9(81.8) \\
2(18.2)\end{array}$ & $\begin{array}{l}4(21.1) \\
8(42.1) \\
7(36.8)\end{array}$ & $\begin{array}{c}4(13.3) \\
17(56.7) \\
9(30)\end{array}$ & 0.108 \\
\hline PV thrombosis, n (\%) & $5(19.2)$ & $15(18.8)$ & $21(19.6)$ & $>0.99$ \\
\hline Metastasis, n (\%) & $4(10.3)$ & $9(10.8)$ & $14(11.4)$ & $>0.99$ \\
\hline
\end{tabular}

Percentages are given as valid percent

AFP, $\alpha$-fetoprotein; HBV, hepatitis B virus; HCC, hepatocellular carcinoma; HCV, hepatitis C virus; $P V$, portal vein; IQR, interquartile range; CT, computed tomography; MRI, magnetic resonance imaging

HCV and HBV ( $\mathrm{P}=0.005)$, with $\mathrm{HCV}$ patients being diagnosed more often before the age of $60(\mathrm{P}=0.032)$. HBV and nvLD patients were $100 \%$ of Caucasian race, while the percentage dropped for HCV patients to $89.7 \%(\mathrm{P}=0.035)$. Cirrhosis was present in $85.6 \%, 93.1 \%$ and $79.5 \%$ of HBV, HCV and nvLD patients respectively, with a difference among all 3 groups only marginally non-significant $(\mathrm{P}=0.054)$. When $\mathrm{HCV}$ and nvLD patients were compared separately regarding the absence of cirrhosis, the proportion of the latter was found to be significantly higher $(\mathrm{P}<0.004)$. A trend was also observed in relation to the tumor location $(\mathrm{P}=0.067)$. The right lobe was the predominant one for all 3 groups (HBV: $73.5 \%$. HCV: $55.6 \%$, nvLD: $48.8 \%$ ) with the percentage of patients with right-lobe HCC differing significantly between HBV and nvLD 
Table 2 Differences among HCC characteristics according to etiology (2000-2019), Greece

\begin{tabular}{|c|c|c|c|c|}
\hline Characteristics & $\mathrm{HBV}$ & $\mathrm{HCV}$ & Non-viral & P-value \\
\hline Age, median (IQR) & $66(15)^{\%}$ & $57(17)^{\%, \&}$ & $69(14)^{8}$ & $\leq 0.005$ \\
\hline$<60, \mathrm{n}(\%)$ & $11(23.9)^{*}$ & $19(50)^{*}$ & $10(27)$ & 0.032 \\
\hline Male, n (\%) & $124(92.5)^{*}$ & $58(75.3)^{*}$ & $76(85.4)$ & 0.002 \\
\hline White, n (\%) & $46(100 \%)$ & $35(89.7)$ & $38(100)$ & 0.035 \\
\hline Cirrhotic, n (\%) & $107(85.6)$ & $67(93.1)^{*}$ & $66(79.5)^{*}$ & 0.054 \\
\hline $\begin{array}{l}\text { Child-Pugh score, n (\%) } \\
\text { A } \\
\text { B } \\
\text { C }\end{array}$ & $\begin{array}{c}43(50.6) \\
33(38.8) \\
9(10.6)\end{array}$ & $\begin{array}{c}22(45.8) \\
21(43.8) \\
5(10.4)\end{array}$ & $\begin{array}{c}28(50) \\
18(32.1) \\
10(17.9)\end{array}$ & 0.62 \\
\hline $\begin{array}{l}\text { HCC diagnosis, n (\%) } \\
\text { CT } \\
\text { MRI } \\
\text { Biopsy }\end{array}$ & $\begin{array}{l}15(32.6) \\
19(41.3) \\
12(26.1)\end{array}$ & $\begin{array}{c}10(33.3) \\
15(50) \\
5(16.7)\end{array}$ & $\begin{array}{l}11(29.7) \\
12(32.4) \\
14(37.8)\end{array}$ & 0.406 \\
\hline $\begin{array}{l}\text { Nodules, } \mathrm{n}(\%) \\
<3 \text { nodules } \\
\text { diameter: }<3 \mathrm{~cm} \\
\geq 3,<5 \mathrm{~cm} \\
\geq 5 \mathrm{~cm}\end{array}$ & $\begin{array}{c}99(80.5) \\
6(13.6) \\
19(43.2)^{\star} \\
19(43.2)\end{array}$ & $\begin{array}{c}54(77.1) \\
7(21.9) \\
12(37.5) \\
13(40.6)\end{array}$ & $\begin{array}{l}69(83.1) \\
9(19.1) \\
9(19.1)^{\star} \\
29(61.7)\end{array}$ & $\begin{array}{l}0.650 \\
0.106\end{array}$ \\
\hline $\begin{array}{l}\text { Location (lobe) } \\
\text { Right } \\
\text { Left } \\
\text { Right and left }\end{array}$ & $\begin{array}{c}50(73.5)^{\star} \\
9(13.2) \\
9(13.2)\end{array}$ & $\begin{array}{c}25(55.6) \\
7(15.6) \\
13(28.9)\end{array}$ & $\begin{array}{c}20(48.8)^{*} \\
9(22) \\
12(29.3)\end{array}$ & 0.067 \\
\hline $\begin{array}{l}\text { AFP, median (IQR) } \\
<350 \mathrm{ng} / \mathrm{mL}, \mathrm{n}(\%)\end{array}$ & $76(65)$ & $31(56.4)$ & $41(57.7)$ & 0.444 \\
\hline $\begin{array}{l}\text { Differentiation, n (\%) } \\
\text { Low } \\
\text { Intermediate } \\
\text { High } \\
\text { PV thrombosis, n (\%) } \\
\text { Metastasis, n (\%) }\end{array}$ & $\begin{array}{c}0 \\
4(50) \\
4(50) \\
4(10.8) \\
6(13.6)\end{array}$ & $\begin{array}{c}2(33.3) \\
3(50) \\
1(16.7) \\
9(33.3) \\
1(3.3)\end{array}$ & $\begin{array}{c}2(12.5) \\
10(62.5) \\
4(25) \\
18.6(8) \\
7(14.3)\end{array}$ & $\begin{array}{l}0.093 \\
0.298\end{array}$ \\
\hline
\end{tabular}

Percentages are given as valid percent

*, column proportions that differ significantly; \%,\&, P corresponds to indicated compared proportions

AFP, $\alpha$-fetoprotein; HBV, hepatitis B virus; HCC, hepatocellular carcinoma; HCV, hepatitis C virus; PV, portal vein; IQR, interquartile range; CT, computed tomography; MRI, magnetic resonance imaging

patients $(\mathrm{P}<0.006)$. The remainder of the patient and tumor characteristics did not differ significantly among the 3 groups.

\section{Comparison of periods (Table 1)}

HCC was diagnosed until 2011 (period A) in 94 (31.6\%) and after 2011 (period B) in 203 (68.4\%) of the 297 patients, while the time of HCC diagnosis was unknown for 3 patients, who were excluded from these comparisons. No significant change was observed concerning the patient characteristics or the causes of chronic liver disease between periods A and B. However, there was a trend towards a decreasing proportion of viral etiology, HBV (from $47.9 \%$ to $43.8 \%$ ), and HCV (from $29.8 \%$ to $23.2 \%$ ), with a relative increased proportion of nvLD (from $22.3 \%$ to $33 \%)$ in period B ( $\mathrm{P}=0.075)$ (Fig. 1).

Regarding HCC characteristics, which could reflect the tumor's biological behavior and stage, the proportion

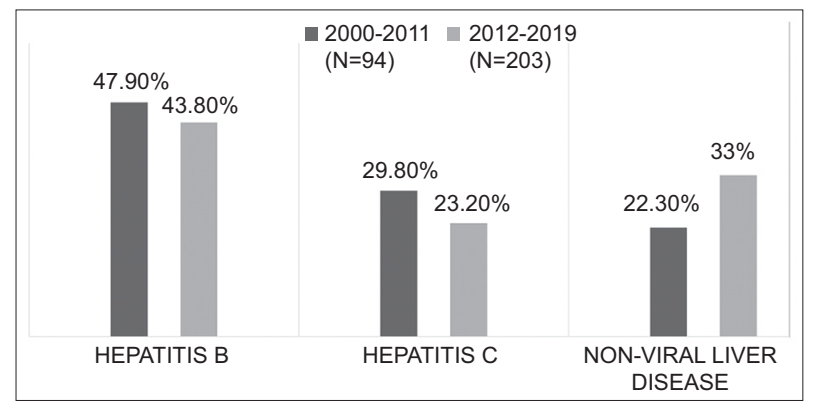

Figure 1 Hepatocellular carcinoma etiology change (2000-2019), Greece

of patients with less than 3 nodules increased in period $\mathrm{B}$ (84.5\%) compared to period A (69.3\%) $(\mathrm{P}=0.006)$. A similar increase was observed in the proportion of patients with nodules less than $3 \mathrm{~cm}(23.5 \%$ in period $\mathrm{B}$ vs $5.3 \%$ in period $\mathrm{A}, \mathrm{P}=0.005$ ). 


\section{Comparison with previous studies (Table 3)}

The findings of our study concerning the prevalence of liver diseases in HCC patients were compared with those from 1558 Greek patients with HCC diagnosed between 1974 and $2000[6,7,14-20]$. In the period after 2000 compared with the period 1974-2000, we observed a significant reduction in the proportion of patients with chronic HBV infection (from 59\% to $45 \%$ ) and an increase in the proportion of patients with chronic HCV infection (13\% to $25 \%)$ and nvLD (28\% to $30 \%)$ $(\mathrm{P}<0.001)$ (Fig. 2).

Table 3 Change in hepatocellular carcinoma etiology (1974-2000 vs. 2000-2019), Greece

\begin{tabular}{lcccc}
\hline Years, n (\%) & HBV & HCV & Non viral & Total \\
\hline $1974-2000$ & $914(59)$ & $205(13)$ & $439(28)$ & 1558 \\
$2000-2020$ & $134(45)$ & $77(26)$ & $89(30)$ & 300 \\
& & & & $\mathrm{P}<0.001$ \\
\hline
\end{tabular}

HBV, hepatitis B virus; $H C V$, hepatitis $C$ virus

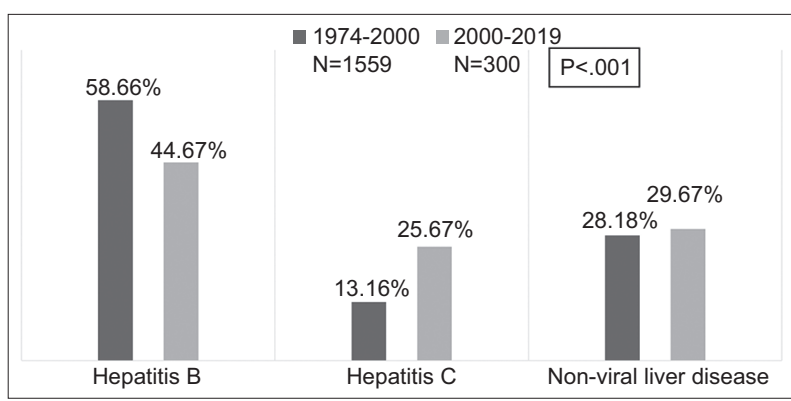

Figure 2 Hepatocellular carcinoma etiology change (1974-2000 vs. 2000-2019), Greece

\section{Discussion}

The incidence and mortality of HCC is changing over time. In North America, where HCC used to have a low incidence, HCC incidence is demonstrating a rapid increase, while traditional high-risk areas in Asia have shown a declining incidence of HCC. This observation is most likely due to changes in exposure to risk factors [4]. On a worldwide scale, $\mathrm{HBV}$ is the leading cause of HCC today, followed by alcohol, $\mathrm{HCV}$, and other causes of chronic liver disease, including NAFLD [21]. In the United States, the increasing incidence is mainly due to an aging population infected with HCV, an increase in HBV incidence, mainly among immigrants from endemic countries, and the increasing rate of NAFLD. The leading cause of HCC in most of Asia is HBV, although with a decreasing rate, while rapid socioeconomic development has caused a substantial increase in NAFLD-related HCC [22]. In Europe, the epidemiology of HCC is heterogeneous and varies among different countries. Overall, in Europe, HCV is the major risk factor, similarly to the United States, mainly because of its predominance in western Europe. In contrast, in central and eastern Europe, ALD prevails as an HCC cause $[23,24]$.

In Greece, chronic viral hepatitis, and mainly HBV, has been over time the predominant cause of HCC. However, when we compared the periods before and after 2000, we observed a substantial decrease in the prevalence of $\mathrm{HBV}$, with a parallel increase in HCV and nvLDs. Furthermore, the data from the last 2 decades (before and after 2011) showed a tendency towards both a decrease in viral hepatitis and a relative increase in nvLD.

The implementation of national HBV immunization in infancy has led to a decrease in HBV prevalence in patients with chronic liver disease, and consequently to a lessening of the burden of HCC in countries with high or intermediate HBV prevalence, including Greece [9,10,24]. Furthermore, long-term effective treatment in patients with chronic hepatitis $\mathrm{B}$ has also contributed in the reduction of HBVrelated HCC over the last decades [25,26]. Regarding HCV infection, the combination of better national screening programs and the availability of effective treatment with direct-acting antivirals is leading to a worldwide reduction in the incidence of HCV related HCC [27]. Diagnosis and treatment before the development of cirrhosis is the ideal goal, since patients with $\mathrm{HCV}$ cirrhosis remain at risk for HCC even after HCV clearance [28]. Thus, a further decrease in the incidence of HCV-related HCC is anticipated in the coming decades, thanks to the implementation of the aforementioned interventions [29]. ALD, and particularly alcoholic cirrhosis, has a causal relationship with the development of HCC and is the leading contributor to HCC in many developed countries. As prevalence rates of chronic viral hepatitis are decreasing, ALD together with NAFLD are expected to play a more important role as risk factors for HCC worldwide, as well as in Greece. There is growing evidence of the increasing contribution of NAFLD to the worldwide HCC incidence. Additionally to the estimated $10-30 \%$ of NAFLD patients who progress to cirrhosis, over one-fourth of nonalcoholic steatohepatitis-related HCC cases can occur in the absence of cirrhosis [24,30]. Although patients with NAFLD have a lower risk for HCC than patients with chronic viral hepatitis, the epidemic of the metabolic syndrome, especially in the developed world, could make NAFLD a major cause of HCC $[24,30]$.

Surveillance strategies applied during the last decades in patients with increased risk for HCC aim at diagnosing HCC in earlier stages, when patients can benefit from more effective treatment offering longer survival. Many studies have been published, highlighting the better tumor characteristics and the survival benefit in patients who participate in surveillance programs [24]. We compared tumor and patient characteristics before and after 2011, assuming that patients after 2011 had better compliance with HCC surveillance, following the implementation of the current guidelines. In fact, patients with HCC diagnosed after (rather than before) 2011 more frequently had less than 3 HCC nodules $(\mathrm{P}=0.006)$ and a largest nodule smaller than $3 \mathrm{~cm}(\mathrm{P}=0.005)$. No difference was observed in AFP, an index of tumor aggressiveness, between the 2 periods. This could have been affected by the low overall median AFP 
value at HCC diagnosis in our cohort and the low upper AFP value reported by many Greek laboratories in the past (350 ng/mL), thus limiting the power of our statistical analysis. Additionally, no difference was observed concerning patients' Child class, tumor differentiation or presence of metastases.

Male sex is a known risk factor for HCC, as was also observed in our cohort. The proportion of women with HBV/ HCV-related HCC is significantly lower, mainly because of sexrelated differences in prevalence rates of $\mathrm{HBV} / \mathrm{HCV}$ chronic infection and cirrhosis. In contrast, the proportion of women with HCC increases in HCC associated with nvLD, particularly NAFLD [31]. In our cohort, we observed the highest proportion of men in HBV-related HCC. Surprisingly though, the proportion of men was greater in nvLD than in HCV-related HCC. Additionally, patients with chronic HCV infection were significantly younger at the time of HCC diagnosis, compared to the other patient groups. Variations in age- and sex-specific rates among different regions usually reflect differences in the prevalence rates of chronic viral hepatitis. In Greece, men represent no more than $60 \%$ of the patients infected with $\mathrm{HCV}$, while the median age of $\mathrm{HCV}$ infection is 20 years among intravenous drug users [32].

Lastly, while underlying cirrhosis is observed in the majority of HCC patients, there is a small proportion of them who are non-cirrhotic. In accordance with the existing literature, absence of cirrhosis in our HCC patients was observed in $14 \%$ of patients with chronic HBV infection, $7 \%$ of patients with chronic $\mathrm{HCV}$ infection and $20 \%$ of patients with nvLD. Namely, $20 \%$ of HCC cases are reported to develop in non-cirrhotic patients [33]. F3 fibrosis in NAFLD, $\mathrm{HBV}$ and $\mathrm{HCV}$ is associated with an increased risk for HCC. Especially for NAFLD, a strong pathogenetic association has been suggested between fatty liver, lipotoxicity and HCC, irrespective of cirrhosis [33]. This is in addition to the comorbidities that usually exist, such as obesity and diabetes mellitus, also independent risk factors for HCC. HBV, irrespective of fibrosis stage, can integrate in hepatic cells and act as a direct mutagenic agent [33]. Lastly, the coexistence of hepatic steatosis, diabetes or alcohol abuse with other (usually viral) liver diseases also increases the risk for HCC in noncirrhotic patients [33].

Our study admittedly has some limitations. Most importantly, it is a retrospective cohort study based on patient records from 2 large academic departments. It should be noted, however, that the 2 participating hospitals represent the 2 main liver units of Athens, Greece, and the reference centers for many areas throughout the country (no discrepancies have been reported in different regions of Greece $[9,34]$ ). The homogeneity of our data can be further supported by the fact that there was no significant difference between the patients coming from the 2 participating hospitals. Confirmed liver diseases were grouped into 3 categories, $\mathrm{HBV}$ and $\mathrm{HCV}$, the 2 main known etiologies of HCC, and non-viral liver diseases. The third group was comprised of all nvLD to avoid misclassification between ALD and NAFLD, particularly before 2011. The retrospective nature of our study resulted in missing or incomplete data for specific covariates, although the diagnosis of chronic liver disease was available for all 300 patients and the date of HCC diagnosis was available in all but 3 patients. AFP was analyzed as a categorical value, since $350 \mathrm{ng} / \mathrm{mL}$ represented the upper reported limit of AFP for some laboratories during an early period of the study. Finally, the sample size, although large considering the population of Greece and previous relevant studies, could have created potential limitations. The creation of national patient registries could offer the opportunity for larger samples and more robust conclusions.

In conclusion, our study reports the characteristics of patients with HCC in a representative cohort seen at tertiary liver centers in Greece. Chronic infections with hepatitis viruses continue to represent the main risk factor for HCC, while the proportion of HBV is decreasing over time, though it still remains the predominant factor. The proportion of $\mathrm{HCV}$-related HCC seems to have a trend towards a decrease and is anticipated to decrease further in the coming decades, thanks to the effective treatment options and our national elimination plan. In contrast, the proportion of nvLD-related

\section{Summary Box}

\section{What is already known:}

- Liver cancer is the sixth most common cancer and the third leading cause of cancer death globally

- Hepatocellular carcinoma (HCC) represents 75$85 \%$ of all liver cancers

- HCC is mainly associated with hepatitis B (HBV) and $\mathrm{C}(\mathrm{HCV})$ virus, excessive alcohol consumption, diabetes, and nonalcoholic fatty liver disease, with wide geographical variations

\section{What the new findings are:}

- After 2000, in Greece, we observed a significant reduction in the proportion of patients with $\mathrm{HBV}$ and an increase in the proportion of patients with HCV infection and non-viral liver diseases (nvLD), although HBV remained the predominant risk factor

- After 2011, in Greece, there was a trend towards a decreasing proportion of both viral etiologies (HBV and HCV), with a relative increased proportion of nvLD

HCC is increasing and will probably play a major role in HCC development in Greek patients in the future.

\section{References}

1. Sung H, Ferlay J, Siegel RL, et al. Global cancer statistics 2020: GLOBOCAN estimates of incidence and mortality worldwide for 
36 cancers in 185 countries. CA Cancer J Clin 2021;71:209-249.

2. Arnold M, Abnet CC, Neale RE, et al. Global burden of 5 major types of gastrointestinal cancer. Gastroenterology 2020;159:335-349.

3. GBD 2017 Stomach Cancer Collaborators. The global, regional, and national burden of stomach cancer in 195 countries, 19902017: a systematic analysis for the Global Burden of Disease study 2017. Lancet Gastroenterol Hepatol 2020;5:42-54.

4. Kulik L, El-Serag HB. Epidemiology and management of hepatocellular carcinoma. Gastroenterology 2019;156:477-491.

5. Koulouris A, Tsagkaris C, Spyrou V, Pappa E, Troullinou A, Nikolaou M. Hepatocellular carcinoma: an overview of the changing landscape of treatment options. J Hepatocell Carcinoma 2021;8:387-401.

6. Raptis I, Koskinas J, Emmanouil T, Hadziyannis S. Changing relative roles of hepatitis $\mathrm{B}$ and $\mathrm{C}$ viruses in the aetiology of hepatocellular carcinoma in Greece. Epidemiological and clinical observations. J Viral Hepat 2003;10:450-454.

7. Kuper HE, Tzonou A, Kaklamani E, et al. Hepatitis B and C viruses in the etiology of hepatocellular carcinoma; a study in Greece using third-generation assays. Cancer Causes Control 2000;11:171-175.

8. Karageorgos SA, Stratakou S, Koulentaki M, et al. Long-term change in incidence and risk factors of cirrhosis and hepatocellular carcinoma in Crete, Greece: a 25-year study. Ann Gastroenterol 2017;30:357-363.

9. Giannousis IP, Papatheodoridis GV, Deutsch MJ, et al. The burden and recent epidemiological changes of the main chronic liver diseases in a Greek referral tertiary centre. Eur J Gastroenterol Hepatol 2010;22:172-179.

10. Stamouli M, Gizaris V, Totos G, Papaevangelou G. Decline of hepatitis B infection in Greece. Eur J Epidemiol 1999;15:447-449.

11. Younossi ZM. Non-alcoholic fatty liver disease - a global public health perspective. J Hepatol 2019;70:531-544.

12. Zois CD, Baltayiannis GH, Bekiari A, et al. Steatosis and steatohepatitis in postmortem material from Northwestern Greece. World J Gastroenterol 2010;16:3944-3949.

13. Papatheodoridis GV, Goulis J, Christodoulou D, et al. High prevalence of elevated liver enzymes in blood donors: associations with male gender and central adiposity. Eur J Gastroenterol Hepatol 2007;19:281-287.

14. Hadziyannis SJ. Detection of HBAg by passive haemagglutination. Lancet 1974;2:344-345.

15. Trichopoulos D, Tabor E, Gerety RJ, et al. Hepatitis B and primary hepatocellular carcinoma in a European population. Lancet 1978;2:1217-1219.

16. Zavitsanos X, Hatzakis A, Kaklamani E, et al. Association between hepatitis $\mathrm{C}$ virus and hepatocellular carcinoma using assays based on structural and nonstructural hepatitis $\mathrm{C}$ virus peptides. Cancer Res 1992;52:5364-5367.

17. Hadziyannis SJ, Giannoulis G, Hadziyannis E, et al. Hepatitis C virus infection in Greece and its role in chronic liver disease and hepatocellular carcinoma. J Hepatol 1993;17(Suppl 3):S72-S77.

18. Hadziyannis S, Tabor E, Kaklamani E, et al. A case-control study of hepatitis $\mathrm{B}$ and $\mathrm{C}$ virus infections in the etiology of hepatocellular carcinoma. Int J Cancer 1995;60:627-631.

19. Bréchot C, Jaffredo F, Lagorce D, et al. Impact of HBV, HCV and
GBV-C/HGV on hepatocellular carcinomas in Europe: results of a European concerted action. J Hepatol 1998;29:173-183.

20. Goritsas CP, Athanasiadou A, Arvaniti A, Lampropoulou-Karatza C. The leading role of hepatitis $\mathrm{B}$ and $\mathrm{C}$ viruses as risk factors for the development of hepatocellular carcinoma. A case control study. J Clin Gastroenterol 1995;20:220-224.

21. Akinyemiju T, Abera S, Ahmed M, et al; Global Burden of Disease Liver Cancer Collaboration. The burden of primary liver cancer and underlying etiologies from 1990 to 2015 at the global, regional, and national level: results from the Global Burden of Disease Study 2015. JAMA Oncol 2017;3:1683-1691.

22. Zhuo Y CQ, Chhatwal J. Changing epidemiology of hepatocellular carcinoma and role of surveillance. 2019 Aug 6. In: Hoshida Y, editor. Hepatocellular carcinoma: translational precision medicine approaches. Internet: Cham (CH): Humana Press; 2019.

23. Childs A, O'Beirne J, Meyer T. Status of hepatocellular cancer in Europe. Chin Clin Oncol 2013;2:44.

24. Singal AG, Lampertico P, Nahon P. Epidemiology and surveillance for hepatocellular carcinoma: new trends. J Hepatol 2020;72: 250-261.

25. European Association for the Study of the Liver. EASL Clinical Practice Guidelines: Management of hepatocellular carcinoma. J Hepatol 2018;69:182-236.

26. Papatheodoridis GV, Lampertico P, Manolakopoulos S, Lok A. Incidence of hepatocellular carcinoma in chronic hepatitis B patients receiving nucleos(t)ide therapy: a systematic review. J Hepatol 2010;53:348-356.

27. Kanwal F, Kramer J, Asch SM, Chayanupatkul M, Cao Y, ElSerag HB. Risk of hepatocellular cancer in HCV patients treated with direct-acting antiviral agents. Gastroenterology 2017;153:996-1005.

28. Ioannou GN, Beste LA, Green PK, et al. Increased risk for hepatocellular carcinoma persists up to 10 years after HCV eradication in patients with baseline cirrhosis or high FIB-4 scores. Gastroenterology 2019;157:1264-1278.

29. Papatheodoridis GV, Goulis J, Sypsa V, et al. Aiming towards hepatitis C virus elimination in Greece. Ann Gastroenterol 2019;32:321-329.

30. Ioannou GN. Epidemiology and risk-stratification of NAFLDassociated HCC. J Hepatol Aug 25 [Online ahead of print]. doi: 10.1016/j.jhep.2021.08.012

31. Wu EM, Wong LL, Hernandez BY, et al. Gender differences in hepatocellular cancer: disparities in nonalcoholic fatty liver disease/steatohepatitis and liver transplantation. Hepatoma Res 2018;4:66.

32. Raptopoulou M, Touloumi G, Tzourmakliotis D, et al. Significant epidemiological changes in chronic hepatitis $\mathrm{C}$ infection: results of the nationwide HEPNET-GREECE cohort study. Hippokratia 2011;15:26-31.

33. Desai A, Sandhu S, Lai JP, Sandhu DS. Hepatocellular carcinoma in non-cirrhotic liver: A comprehensive review. World J Hepatol 2019;11:1-18.

34. Raptopoulou M, Papatheodoridis G, Antoniou A, et al. Epidemiology, course and disease burden of chronic hepatitis B virus infection. HEPNET study for chronic hepatitis B: a multicentre Greek study. J Viral Hepat 2009;16:195-202. 